\title{
Minimum inhibitory concentrations of frequently used antibiotics against Escherichia coli and Trueperella pyogenes isolated from uteri of postpartum dairy cows
}

\author{
A. Pohl, ${ }^{*}$ A. Lübke-Becker,† and W. Heuwieser*1 \\ ${ }^{*}$ Clinic of Animal Reproduction, Faculty of Veterinary Medicine, Freie Universität Berlin, Königsweg 65, 14163 Berlin, Germany \\ †Institute of Microbiology and Epizootics, Faculty of Veterinary Medicine, Freie Universität, Berlin, Robert-von-Ostertag-Str. 7-13, \\ 14163 Berlin, Germany
}

\begin{abstract}
The objective of this study was to determine minimum inhibitory concentrations (MIC) of frequently used antimicrobials for Escherichia coli and Trueperella pyogenes isolated from postpartum bovine uteri of cows with acute puerperal metritis (APM, $\mathrm{n}=67)$, cows suspected to have APM $(\mathrm{n}=37)$, and healthy cows (n $=37$ ) and to evaluate possible differences in MIC according to clinical signs. Cows with APM had reddishbrown, fetid vaginal discharge and rectal temperature (RT) $\geq 39.5^{\circ} \mathrm{C}$ within $21 \mathrm{~d}$ in milk; cows suspected to have APM had either reddish-brown, fetid vaginal discharge or $\mathrm{RT} \geq 39.5^{\circ} \mathrm{C}$ within $21 \mathrm{~d}$ in milk; and healthy cows had neither fetid discharge nor $\mathrm{RT} \geq 39.5^{\circ} \mathrm{C}$. Samples were collected from cows on commercial dairy herds $(\mathrm{n}=7)$ using the cytobrush technique. A total of $37 \mathrm{~T}$. pyogenes isolates and $85 \mathrm{E}$. coli isolates were tested. Ceftiofur, a third-generation cephalosporin that is often used to treat APM, was the focus of analysis. Trueperella pyogenes and E. coli were isolated more often from samples of cows with APM (46 and 90\%, respectively) compared with samples from healthy cows (19 and 54\%, respectively). Regarding cows suspected to have APM, T. pyogenes and E. coli were numerically more often isolated (30 and 70\%, respectively) than in healthy cows (19 and 54\%, respectively). Minimum inhibitory concentrations of ceftiofur were low. For $T$. pyogenes and E. coli, $\mathrm{MIC}_{50}$ (concentration that inhibited growth of $50 \%$ of isolates) were 0.25 and $0.5 \mu \mathrm{g} /$ $\mathrm{mL}$ and $\mathrm{MIC}_{90}$ (concentration that inhibited growth of $90 \%$ of isolates) were 0.5 and $1 \mu \mathrm{g} / \mathrm{mL}$, respectively. Although ceftiofur inhibited all T. pyogenes at the highest concentration tested $(64 \mu \mathrm{g} / \mathrm{mL})$, the growth of $5.9 \%$ of E. coli was not impaired. Recently, ampicillin has been suggested as an alternative treatment for
\end{abstract}

Received February 6, 2017.

Accepted September 23, 2017.

${ }^{1}$ Corresponding author: w.heuwieser@fu-berlin.de
APM. Although the T. pyogenes isolates exhibited low $\mathrm{MIC}$ in general $\left(\mathrm{MIC}_{50} \leq 0.015 \mu \mathrm{g} / \mathrm{mL}\right.$ and $\mathrm{MIC}_{90}=$ $0.06 \mu \mathrm{g} / \mathrm{mL}$ ) and $81.1 \%$ of all T. pyogenes could be inhibited at the lowest ampicillin concentration tested, $11.8 \%$ of the $E$. coli isolates were not impaired at the highest concentration $(64 \mu \mathrm{g} / \mathrm{mL})$ tested in this study. The $\mathrm{MIC}_{50}$ and $\mathrm{MIC}_{90}$ of E. coli were 4 and $\geq 128 \mu \mathrm{g} /$ $\mathrm{mL}$, respectively. We detected no difference in the MIC distributions of ceftiofur or ampicillin among isolates from the 3 APM groups. In summary, E. coli with high MIC against ceftiofur as well as against ampicillin were found in this study.

Key words: minimum inhibitory concentration, antimicrobial susceptibility, antibiotic, metritis

\section{INTRODUCTION}

Infectious uterine diseases are common in dairy cows, with an incidence of acute puerperal metritis (APM) between 14.8 and $40.9 \%$ (Chapinal et al., 2011; Sannmann et al., 2013; Lima et al., 2014). Acute puerperal metritis is characterized by reddish-brown, fetid, watery vaginal discharge and rectal temperature (RT) $\geq 39.5^{\circ} \mathrm{C}$ within the first $21 \mathrm{DIM}$, and it leads to pain response detectable during transrectal palpation (Sheldon et al., 2006; Stojkov et al., 2015). Different aerobic and anaerobic bacteria can be isolated from the infected uterus, including Escherichia coli, Trueperella pyogenes, Prevotella spp., Fusobacterium necrophorum, Fusobacterium nucleatum, Mannheimia haemolytica, Staphylococcus spp., and Streptococcus spp. (Sheldon et al., 2004; Williams et al., 2005; Santos et al., 2011). Trueperella pyogenes and E. coli are known to cause endometrial lesions and therefore are considered the major pathogens associated with APM (Sheldon et al., 2004; Santos et al., 2010b; de Boer et al., 2015). Because of the wide range of potential pathogens, antimicrobials with broad-spectrum activity are primarily indicated, and APM is commonly treated with ceftiofur, a third-generation cephalosporin (Lima 
et al., 2014; Machado et al., 2014). The reason for the widespread use of ceftiofur administered parenterally is its high efficacy (Drillich et al., 2001; Chenault et al., 2004). Moreover, there is no withdrawal time for milk because the amounts of residue appearing in milk are below the tolerance for human consumption (Scientific Advisory Group on Antimicrobials of the Committee for Medicinal Products for Veterinary Use, 2009; Lima et al., 2014). Third-generation cephalosporins, however, are characterized as critically important antimicrobials for human and veterinary medicine (World Health Organization, 2013; World Organization for Animal Health, 2015) and their use in food-producing animals could lead to an increased prevalence of resistance (Scientific Advisory Group on Antimicrobials of the Committee for Medicinal Products for Veterinary Use, 2009). As antibiotic resistance is recognized as a top public health challenge of the 21st century (Thomson et al., 2004; Centers for Disease Control, 2015), veterinarians should support the prudent use of antimicrobials as a risk management option to reduce the emergence and spreading of resistances.

When deciding on antimicrobial treatment, susceptibility testing of pathogens is advisable to select an appropriate antimicrobial (Sheldon et al., 2004; Pyorala et al., 2014). Minimum inhibitory concentrations can be determined by the broth dilution method for various pathogens. This methodology is also suitable for monitoring resistance over time (Cortinhas et al., 2013). The Clinical and Laboratory Standards Institute (CLSI) and the European Committee on Antimicrobial Susceptibility Testing (EUCAST) provide clinical breakpoints of MIC for different veterinary and human pathogens and antimicrobials. Clinical breakpoints are determined by a review of MIC distribution data, pharmacokinetic-pharmocodynamic parameters, and clinical response and should be used in routine clinical laboratory work to inform the choice of therapy in the patient (Silley, 2012; EUCAST 2013). The CLSI defines an isolate as susceptible when the infection may be appropriately treated with the dosage regimen of an antimicrobial agent recommended for that type of infection and infecting species. No MIC clinical breakpoints to classify pathogens into susceptible, intermediate, or resistant, however, have been established for bovine uterus-borne E. coli or T. pyogenes (de Boer et al., 2015). Application of clinical breakpoints of other host species, pathogens, antimicrobial agents, or diseases (e.g., human breakpoints or breakpoints for bovine mastitis) as interpretive criteria is questionable (Werckenthin et al., 2007), and in vitro susceptibility of a specific pathogen does not guarantee clinical outcome (Giguère and Tessmann, 2011). To reduce confusion in terminology, EUCAST introduced the definition of epidemiological cut-off values in contrast to clinical breakpoints. Epidemiological cut-off values are determined exclusively by the distribution of MIC values, are independent of dosing regimens, and are used to detect development of microbiological resistance to antimicrobial agents (Dalhoff et al., 2009; EUCAST, 2013). This illustrates the need of comparable MIC data for bovine uterine pathogens for future development of clinical breakpoints as well as epidemiological cut-off values for rational therapy and monitoring of MIC values over time.

In 2002 and 2003, ceftiofur hydrochloride (Excenel RTU, Zoetis, Parsippany, NJ) was initially approved for treatment of APM in the United States (US FDA, 2002) and Germany (iMedikament, 2003). Only a few studies have evaluated MIC for pathogens originating from the bovine uterus; therefore, limited data on in vitro susceptibilities or the development of resistance of pathogens against ceftiofur are available (Sheldon et al., 2004; Santos et al., 2010a,b; de Boer et al., 2015). Moreover, little is known about the relation between MIC and clinical signs of disease.

Therefore, the main objective of this study was to assess MIC of commonly used antibiotics for the major APM-causing bacteria E. coli and T. pyogenes isolated from postpartum bovine uteri of cows housed on 7 farms in Germany. Moreover, MIC according to clinical symptoms of APM were evaluated.

\section{MATERIALS AND METHODS}

\section{Farms and Cows}

Samples were collected from a convenience sample of dairy cows with median DIM of 6 (interquartile range: 4 to 7 ) in 7 commercial farms in northeastern Germany from June 2013 to February 2015 as part of a previously published study on the treatment of APM (Pohl et al., 2016). Body temperature and vaginal discharge of early lactation cows were evaluated daily by trained farm personnel. Farms were visited every other week and diagnoses were confirmed before samples of cows with APM (i.e., 2 clinical signs of APM: reddish-brown, fetid vaginal discharge and $\mathrm{RT} \geq 39.5^{\circ} \mathrm{C}$ within $21 \mathrm{DIM}$, $\mathrm{n}=67$ ); cows suspected to have APM (i.e., 1 clinical sign of APM: reddish-brown, fetid vaginal discharge or $\mathrm{RT} \geq 39.5^{\circ} \mathrm{C}$ within $21 \mathrm{DIM}, \mathrm{n}=37$ ); and healthy cows (i.e., no clinical signs of APM: no discharge or non-fetid lochia and $\mathrm{RT}<39.5^{\circ} \mathrm{C}, \mathrm{n}=37$ ) were taken.

Participating farms were recruited based on convenience. Herd size ranged from 732 to 2,244 with 677 to 1,319 milking cows. Cows were managed according to the guidelines set by the International Cooperation on Harmonisation of Technical Requirements for Regis- 
tration of Veterinary Medical Products (Hellmann and Radeloff, 2000). The experimental procedures reported herein were conducted with the approval of the Institutional Animal Care and Use Committee of Freie Universität Berlin (Germany). Cows were housed indoors in freestall barns with different beddings, (e.g., rubber mats, straw, or dried fermentation product from the onsite biogas plant) and were fed TMR. The TMR fed to prepartum and to early lactation cows were formulated to meet or exceed minimum nutritional requirements for high-producing dairy cows (NRC, 2001). Reproductive performance and medical treatments were recorded and stored by using the herd management software (Herde, version 5.81, dsp Agrosoft GmbH, Ketzin, Germany).

An a priori sample size calculation was not possible, because the prevalence of $E$. coli and $T$. pyogenes and the MIC distributions were unknown for dairy cows in Germany.

\section{Sample Collection}

Sample collection was performed by one veterinarian (A. Pohl) throughout the study. Uterine bacteriological swab samples were collected from the uterine body of cows using the cytobrush technique previously described (Sens and Heuwieser, 2013). In brief, the brush was double-guarded by 2 plastic sheaths that prevented bacterial contamination of the brush with pathogens of origin other than the uterus. The vulva was first dry cleaned with cellulose wipes, and then the cytobrush (CytologyBrush for mares, Minitüb GmbH, Tiefenbach, Germany) was inserted into the vagina and passed through the cervix into the uterus. The internal sheath was then pushed through the rubber cap of the external sheath and the brush was pushed forward and brought into contact with uterine fluids. The brush was then retracted into its sheath and gently pulled out of the uterus. Thereafter, the brush was inserted into transport medium, which contained a balanced formula of reducing agents and resazurin in a buffered isotonic agar base (BBL Port-A-Cul, BD Diagnostics/Diagnostic Systems, Heidelberg, Germany). The sample was then transported to the laboratory (Institute of Microbiology and Epizootics, Faculty of Veterinary Medicine, Freie Universität, Berlin, Germany).

\section{Microbiology}

A total of 141 cytobrush samples were analyzed by aerobic and anaerobic culture after direct inoculation of the cytobrush on suitable agar plates and after enrichment in medium and subsequent culture on agar (all agar purchased from Oxoid, Wesel, Germany). For the detection of aerobic bacteria, Columbia blood agar
(5\% sheep blood), Gassner agar, and Brilliance UTI Clarity agar were inoculated with the cytobrush within $12 \mathrm{~h}$ after sampling for 24 to $48 \mathrm{~h}$ (aerobic, $36^{\circ} \mathrm{C}$ ). For the evaluation of the presence of obligate anaerobic bacteria, inoculation was carried out on Columbia blood agar (5\% sheep blood) with added L-cysteine (Merck, Darmstadt, Germany), hemin (Sigma-Aldrich, Hamburg, Germany), vitamin K1 (Roche, Mannheim, Germany), and lysed sheep blood $0.5 \%$ (Oxoid) and on an additional plate with the same agar plus gentamicin (Hexal, Holzkirchen, Germany), for 48 to $72 \mathrm{~h}$ (anaerobic, $\left.36^{\circ} \mathrm{C}\right)$. Chocolate agar was used for cultivation of fastidious bacteria for 24 to $48 \mathrm{~h}\left(36^{\circ} \mathrm{C}\right.$, microaerobic, $7 \% \mathrm{CO}_{2}$ ). In addition, an enrichment culture with brainheart infusion broth (Oxoid) was inoculated from each cytobrush at $37^{\circ} \mathrm{C}$ for $24 \mathrm{~h}$, which was transferred to Columbia blood agar (5\% sheep blood). Identification of species was carried out by Gram stain, oxidase and catalase tests according to standard operating protocols (Versalovic et al., 2011), and API strips (bioMérieux, Nürtingen, Germany) and verified with matrix-assisted laser desorption/ionization time-of-flight (MALDI TOF) MS (Bruker Daltonik, Bremen, Germany).

After identification, isolates were transferred to brain-heart infusion broth and incubated at $37^{\circ} \mathrm{C}$ until turbidity (indicating bacterial growth) was visible approximately $4 \mathrm{~h}$ later. Eight hundred microliters of the broth was then mixed with $200 \mu \mathrm{L}$ of glycerol and stored at $-70^{\circ} \mathrm{C}$ until used.

\section{MIC Determination}

The pathogens for determination of MIC used in this study included 1 isolate from each cow of which E. coli, T. pyogenes, or both had been isolated. In 16 samples, 2 or 3 phenotypically different strains of $E$. coli were present (according to morphology or hemolysis); in these cases, more than one isolate per cow was analyzed for MIC. The inclusion criterion of isolates for MIC determination was no local or systemic antimicrobial treatment after calving and before sampling. Thus, 12 T. pyogenes and $21 \mathrm{E}$. coli were discarded because inspection of the records found that the cows had been treated before sampling. Seventy-four isolates of metritic cows, 38 isolates of cows suspected to have APM, and 10 isolates of healthy cows were used for analysis. A total of $37 \mathrm{~T}$. pyogenes and $85 \mathrm{E}$. coli isolates were evaluated for determination of MIC.

The broth microdilution method to determine MIC for the E. coli isolates was carried out in accordance with CLSI guidelines (CLSI, 2013). The MIC for $T$. pyogenes was determined using broth microdilution according to recently described protocols (Werckenthin et al., 2007; de Boer et al., 2015). For this, custom-made 
microtiter plates (produced by MCS Diagnostics based on Sensititre, Trek Diagnostic Systems Ltd., Swalmen, the Netherlands) were used. The test ranges for each antimicrobial agent are shown in Table 2 for $T$. pyogenes and Table 3 for $E$. coli. The test media were cation-adjusted Mueller-Hinton broth (E. coli) and cation-adjusted Mueller-Hinton broth supplemented with $2 \%$ (vol/vol) lysed horse blood (T. pyogenes). The microtiter plates were incubated at $35 \pm 2^{\circ} \mathrm{C}$ in ambient air (E. coli) or in a $\mathrm{CO}_{2}$-enriched environment (T. pyogenes) and the results were read after $24 \mathrm{~h}(E$. coli) or $48 \mathrm{~h}$ (T. pyogenes). Trueperella pyogenes ATCC 19411 and E. coli ATCC 25922 were used as quality control strains and were tested 4 and 5 times together with MIC determination. All susceptibility results from quality control strains were within the prescribed ranges.

\section{Statistical Analysis}

The MIC was defined as the lowest concentration of an antimicrobial that inhibited any visible growth of an isolate (Saini et al., 2013). The concentrations that inhibited the growth of $50 \%\left(\mathrm{MIC}_{50}\right)$ and $90 \%\left(\mathrm{MIC}_{90}\right)$ of the isolates was calculated for each antimicrobial (de Boer et al., 2015). Data were analyzed using SPSS for Windows (version 22, SPSS Inc., Munich, Germany) and Medcalc (version 15.0., Mariakerke, Belgium). A binary logistic regression model was used to evaluate the effect of signs indicative of APM (2 signs, 1 sign, no signs) on the occurrence of pathogens. Models were built according to the model-building strategies provided by Dohoo et al. (2009), and cow within farm was included as random effect. Odds ratios for occurrence of pathogens in cows with 2 or 1 signs compared with cows with no signs of APM (reference category) and 95\% confidence intervals were calculated. The effect of signs of APM on MIC of ceftiofur and ampicillin were analyzed in a generalized linear mixed model ANOVA. Minimum inhibitory concentrations were previously log-transformed to achieve a normal distribution of values. Models were, again, built according to the modelbuilding strategies provided by Dohoo et al. (2009) and cow within farm was included as random effect.

\section{RESULTS}

A total of 141 samples were collected from 67 cows with APM, 37 cows suspected to have APM, and 37 healthy cows. Distribution of isolated pathogens considering the clinical signs indicative of APM is given in Table 1. No bacterial growth occurred in 5 samples from healthy cows and in 1 sample of a cow suspected to have APM. Cows with 2 signs of APM had 7.16
(95\% CI: $2.58-19.84 ; P<0.001)$ times the odds of having E. coli compared with healthy cows and $3.69(95 \%$ CI: $1.4-9.73 ; P=0.009)$ times the odds of having $T$. pyogenes compared with healthy cows. Compared with healthy cows, cows with 1 or 2 signs of APM had 6.54 (95\% CI: $1.71-25.06 ; P=0.006)$ or 10.42 (95\% CI: $2.95-36.73 ; P<0.001)$ times the odds of having $\mathrm{Fu}$ sobacterium spp. Moreover, cows with 2 signs of APM had 2.94 (95\% CI: $1.15-7.50 ; P=0.024$ ) times the odds of having Prevotella spp. compared with healthy cows. Cows with 2 signs of APM also had 4.19 (95\% CI: $1.52-11.56 ; P=0.006)$ times the odds of having Bacteroides fragilis compared with healthy cows.

For determination of MIC, 37 T. pyogenes and 85 E. coli from 120 cows were evaluated according to the inclusion criteria described above. Twenty-nine (24\%) and $93(76 \%)$ isolates were obtained from primiparous and multiparous cows, respectively. Frequency distributions of MIC for a range of antimicrobials against $T$. pyogenes and E. coli are given in Tables 2 and 3.

For T. pyogenes, the $\mathrm{MIC}_{50}$ of ceftiofur was $0.25 \mu \mathrm{g} /$ $\mathrm{mL}$ and the $\mathrm{MIC}_{90}$ was $0.5 \mu \mathrm{g} / \mathrm{mL}$. For E. coli, the $\mathrm{MIC}_{50}$ of ceftiofur was $0.5 \mu \mathrm{g} / \mathrm{mL}$ and the $\mathrm{MIC}_{90}$ was $1 \mu \mathrm{g} / \mathrm{mL}$. Variations in distribution of MIC values of ceftiofur for E. coli and T. pyogenes among the 3 study groups are given in Table 4. No differences were found between logMIC of ceftiofur of cows with 2 or 1 signs of APM compared with no signs of APM for T. pyogenes or E. coli $(P=0.321$ or $P=0.515)$. From all $E$. coli recovered from cows with 2 signs of APM, however, $9.8 \%$ were not inhibited at the highest concentration of ceftiofur available. For ampicillin, no differences could be found between $\log$ MIC of cows with 2 or 1 signs of APM compared with no signs of APM for T. pyogenes or $E$. $\operatorname{coli}(P=0.117$ or $P=0.647)$.

The cumulative distribution of MIC of ceftiofur that inhibit the growth of E. coli and T. pyogenes is shown in Figure 1. A summary of MIC values of ceftiofur against T. pyogenes and E. coli from our study and 4 other studies is given in Table 5. The $\mathrm{MIC}_{50}$ and $\mathrm{MIC}_{90}$ of $T$. pyogenes varied by $6(<0.06$ to $2 \mu \mathrm{g} / \mathrm{mL})$ and $9(0.125$ to $32 \mu \mathrm{g} / \mathrm{mL}$ ) doubling dilutions among studies. The $\mathrm{MIC}_{50}$ and $\mathrm{MIC}_{90}$ of E. coli differed by 3 (0.25 to $1 \mu \mathrm{g} /$ $\mathrm{mL})$ and $2(0.5$ to $1 \mu \mathrm{g} / \mathrm{mL})$ doubling dilutions among studies. Three of the studies provided data deriving only from a single farm in the United Kingdom (Sheldon et al., 2004) or the United States (Santos et al., 2010a,b). Samples from another study were collected from pasture-based cows from 7 herds in New Zealand (de Boer et al., 2015). Regarding the latter, differences in bacterial species and strains are likely in contrast to confinement housing, as has been demonstrated for mastitis (McDougall, 2002; Parker et al., 2008; Pyorala and Taponen, 2009). 
Table 1. Frequency distribution [\% of cows (no./total no.)] with clinical signs indicative of acute puerperal metritis (2 signs, 1 sign, no sign) and isolated bacterial species isolated from 141 samples

\begin{tabular}{|c|c|c|c|c|c|}
\hline \multirow[b]{2}{*}{ Isolated pathogen } & \multicolumn{3}{|c|}{ No. of clinical signs of metritis ${ }^{1}$} & \multirow[b]{2}{*}{$P$-value ${ }^{2}$} & \multirow[b]{2}{*}{ Total } \\
\hline & 2 & 1 & 0 & & \\
\hline Escherichia coli & $90(60 / 67)^{\mathrm{b}}$ & $70(26 / 37)^{\mathrm{a}}$ & $54(20 / 37)^{\mathrm{a}}$ & 0.001 & $75(106 / 141)$ \\
\hline Trueperella pyogenes & $46(31 / 67)^{\mathrm{b}}$ & $30(11 / 37)^{\mathrm{ab}}$ & $19(7 / 37)^{\mathrm{a}}$ & 0.021 & $35(49 / 141)$ \\
\hline Streptococcus uberis & $66(44 / 67)$ & $68(25 / 37)$ & $54(20 / 37)$ & 0.419 & $63(89 / 141)$ \\
\hline Streptococcus dysgalactiae & $3(2 / 67)$ & $3(1 / 37)$ & $3(1 / 37)$ & 0.999 & $3(4 / 141)$ \\
\hline Histophilus somni & $11(7 / 67)$ & $11(4 / 37)$ & $5(2 / 37)$ & 0.740 & $9(13 / 141)$ \\
\hline Mannheimia spp. & $8(5 / 67)$ & $5(2 / 37)$ & $8(3 / 37)$ & 0.932 & $7(10 / 141)$ \\
\hline Fusobacterium spp. & $49(33 / 67)^{\mathrm{b}}$ & $38(14 / 37)^{\mathrm{b}}$ & $8(3 / 37)^{\mathrm{a}}$ & 0.002 & $36(50 / 141)$ \\
\hline Prevotella spp. & $45(30 / 67)^{\mathrm{b}}$ & $24(9 / 37)^{a}$ & $22(8 / 37)^{\mathrm{a}}$ & 0.030 & $33(47 / 141)$ \\
\hline Clostridium spp. & $36(24 / 67)$ & $16(6 / 37)$ & $22(8 / 37)$ & 0.082 & $27(38 / 141)$ \\
\hline Bacteroides fragilis & $45(30 / 67)^{\mathrm{b}}$ & $22(8 / 37)^{\mathrm{a}}$ & $16(6 / 37)^{\mathrm{a}}$ & 0.007 & $31(44 / 141)$ \\
\hline Porphyromonas spp. & $39(26 / 67)$ & $27(10 / 37)$ & $16(6 / 37)$ & 0.063 & $30(42 / 141)$ \\
\hline
\end{tabular}

${ }^{\mathrm{a}, \mathrm{b}}$ Values with different superscripts within a row denote significant differences $(P<0.05)$ between cows with 2,1 or 0 signs of metritis.

${ }^{1}$ Two signs $=$ reddish-brown, fetid vaginal discharge and rectal temperature $(\mathrm{RT}) \geq 39.5^{\circ} \mathrm{C}$ within 21 DIM; 1 sign $=$ reddish-brown, fetid vaginal discharge or $\mathrm{RT} \geq 39.5^{\circ} \mathrm{C}$ within $21 \mathrm{DIM} ; 0$ signs $=$ no discharge or nonfetid lochia and $\mathrm{RT}<39.5^{\circ} \mathrm{C}$ within 21 DIM.

${ }^{2} P$-value derived from binary logistic regression to evaluate the effect of signs indicative of acute puerperal metritis on frequencies of isolated pathogens.

\section{DISCUSSION}

Prudent use of antimicrobials in people and in livestock animals is urgently required to address worldwide concerns about emerging resistances. Antibiotics that are used in severely ill humans especially, such as thirdgeneration cephalosporins, should be used with great caution in food-producing animals, and the use of MIC to follow changes in the resistance pattern and possible emergence of resistance has been suggested (Oliveira et al., 2012). Therefore, the objective of this study was to assess MIC of commonly used antibiotics for the major APM-causing bacteria E. coli and T. pyogenes to support responsible and prudent use.

As a prerequisite, we investigated the frequency distribution of bacterial species associated with different clinical signs indicative of APM. Interestingly, $T$. pyogenes and $E$. coli were isolated from cows with or suspected to have APM and from cows without any signs of APM. This is in line with the finding that the development of uterine disease depends not only on the bacterial species present, but also on the immune response of the cow and the bacterial load (Sheldon et al., 2006). Moreover, a certain degree of inflammation is likely necessary to support physiological adaptions after parturition (Bradford et al., 2015). It was shown, however, that intrauterine infusion of $T$. pyogenes caused a massive inflammatory response, demonstrating the negative effect of this bacterium on uterine tissue (Lima et al., 2015). Our results also showed that $E$. coli, T. pyogenes, Fusobacterium spp., and Bacteroides fragilis were isolated more frequently from cows with 2 signs of $\mathrm{APM}\left(\mathrm{RT} \geq 39.5^{\circ} \mathrm{C}\right.$ and fetid, reddish-brown vaginal discharge) compared with cows with no signs of APM. This is in accordance with observations that on d 10 after calving, the prevalence of T. pyogenes, $E$. coli, and Bacteroides spp. was greater in cows with fetid vaginal discharge than in healthy cows (Huszenicza et al., 1999). Furthermore, it has been shown that the presence of abnormal cervical discharge at d 1, 14, and 28 postpartum is positively associated with the presence of T. pyogenes (Dohmen et al., 2000). Also, the occurrence of $E$. coli and its endotoxins in lochia early postpartum promotes the development of uterine infections later postpartum (Dohmen et al., 2000). Moreover, Williams et al. (2005) found that the risk for fetid odor of vaginal mucus was increased when $T$. pyogenes, E. coli, non-hemolytic streptococci, and Mannheimia haemolytica were isolated. To sum up, our study supports the common finding that E. coli and T. pyogenes are likely to be found in cows with APM.

In the next step, we provided MIC data for E. coli and $T$. pyogenes isolated postpartum from indoorhoused cows of 7 commercial farms in Germany. In our study, the $\mathrm{MIC}_{90}$ of ceftiofur for T. pyogenes was lower $(0.5 \mu \mathrm{g} / \mathrm{mL})$ than that reported by Santos et al. (2010a; $32 \mu \mathrm{g} / \mathrm{mL})$ and de Boer et al. $(2015 ; 2 \mu \mathrm{g} / \mathrm{mL}$ ). Although the $\mathrm{MIC}_{50}$ and $\mathrm{MIC}_{90}$ from the latter study (de Boer et al., 2015) were only 2 dilutions greater than the MIC reported here, Santos et al. (2010a) described 3- and 7-fold-greater dilutions for $\mathrm{MIC}_{50}$ and $\mathrm{MIC}_{90}$. The small number of sampled cows combined with up to 8 isolates per sample used for MIC determination by Santos et al. (2010a), as well as differences in methodology, might have contributed to higher MIC in that study and, therefore, should be interpreted with 

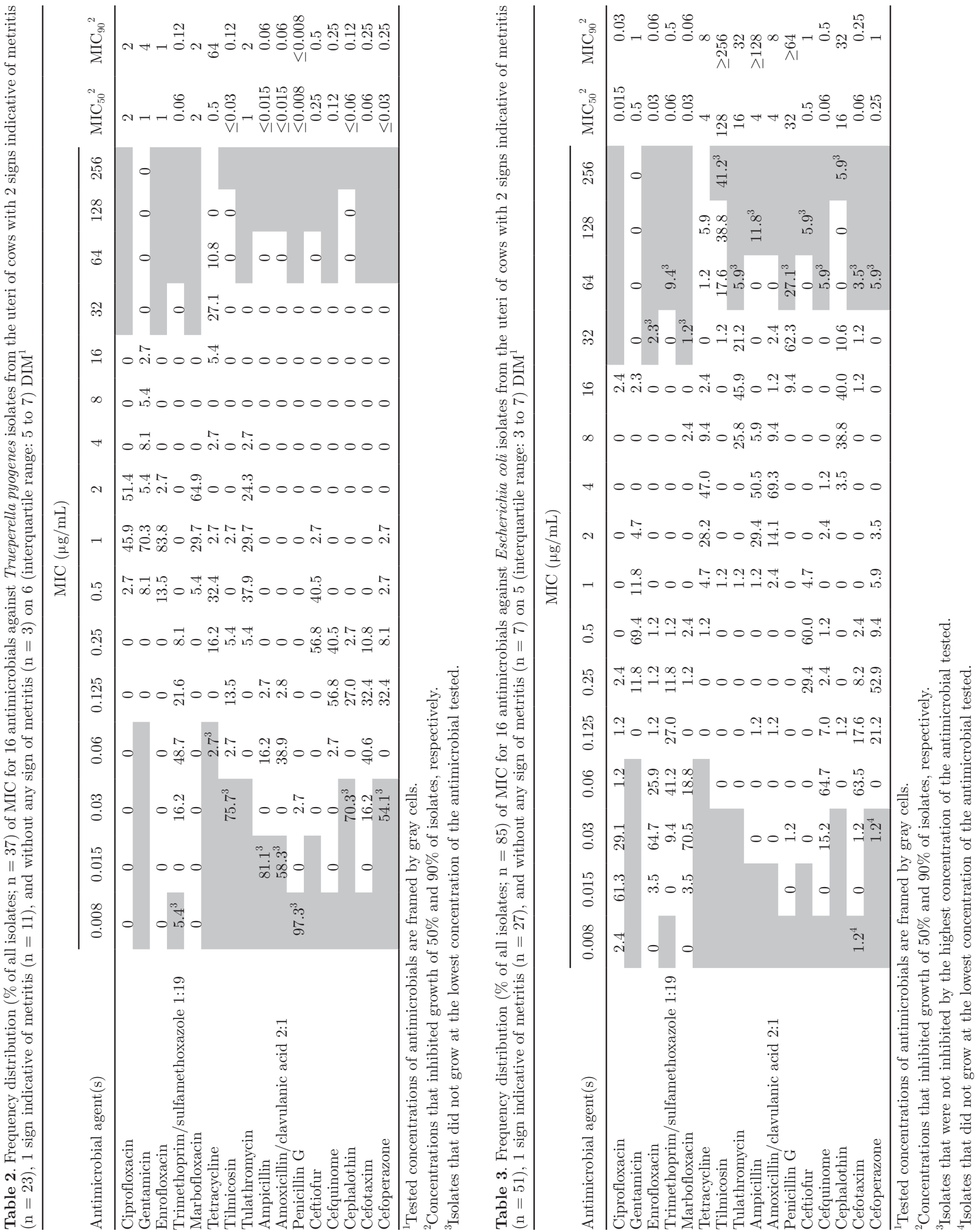
Table 4. Frequency distribution (\% of all isolates) of MIC of ceftiofur against Trueperella pyogenes and Escherichia coli isolates from the uteri of cows considering number of clinical signs indicative for acute puerperal metritis

\begin{tabular}{|c|c|c|c|c|c|c|c|}
\hline \multirow[b]{2}{*}{ Pathogen } & \multirow{2}{*}{$\begin{array}{l}\text { No. of signs of } \\
\text { metritis }^{1}\end{array}$} & \multicolumn{4}{|c|}{$\mathrm{MIC}(\mu \mathrm{g} / \mathrm{mL})$} & \multirow[b]{2}{*}{$\mathrm{MIC}_{50}{ }^{2}$} & \multirow[b]{2}{*}{$\mathrm{MIC}_{90}$} \\
\hline & & 0.25 & 0.5 & 1.0 & $\geq 64$ & & \\
\hline \multirow[t]{3}{*}{ T. pyogenes } & $2(\mathrm{n}=23)$ & 52.17 & 47.83 & 0 & 0 & 0.25 & 0.5 \\
\hline & $1(\mathrm{n}=11)$ & 54.55 & 36.36 & 9.09 & 0 & 0.25 & 0.5 \\
\hline & $0(\mathrm{n}=3)$ & 100.00 & 0 & 0 & 0 & 0.25 & 0.25 \\
\hline \multirow[t]{3}{*}{ E. coli } & $2(\mathrm{n}=51)$ & 37.25 & 49.02 & 3.92 & 9.80 & 0.5 & 1.0 \\
\hline & $1(\mathrm{n}=27)$ & 18.52 & 74.07 & 7.41 & 0 & 0.5 & 1.0 \\
\hline & $0(\mathrm{n}=7)$ & 14.29 & 85.71 & 0 & 0 & 0.5 & 0.5 \\
\hline
\end{tabular}

${ }^{1}$ Two signs $=$ reddish-brown, fetid vaginal discharge and rectal temperature $(\mathrm{RT}) \geq 39.5^{\circ} \mathrm{C}$ within 21 DIM; 1 sign $=$ reddish-brown, fetid vaginal discharge or $\mathrm{RT} \geq 39.5^{\circ} \mathrm{C}$ within $21 \mathrm{DIM} ; 0$ signs $=$ no discharge or nonfetid lochia and $\mathrm{RT}<39.5^{\circ} \mathrm{C}$ within 21 DIM.

${ }^{2}$ Concentrations that inhibited growth of $50 \%$ and $90 \%$ of isolates, respectively.

caution. Analyzing MIC, however, was only a secondary outcome of Santos et al. (2010a). In contrast, the $\mathrm{MIC}_{90}$ values for T. pyogenes reported in our study were greater than those from Sheldon et al. (2004; $0.125 \mu \mathrm{g} /$ $\mathrm{mL}$ ). In the absence of epidemiological or clinical interpretive criteria, interpretation of our MIC remains speculative. It has been reported, however, that mean concentrations of potentially active ceftiofur derivates in serum, endometrium, and lochia after administration of the European Union-approved dosage of $1.1 \mathrm{mg} / \mathrm{kg}$ on 3 consecutive days remained greater than $0.5 \mu \mathrm{g} / \mathrm{mL}$ (or $\mu \mathrm{g} / \mathrm{mg}$ ) for the entire dosing interval (Drillich et al., 2006). This concentration exceeds the $\mathrm{MIC}_{90}$ for T. pyogenes reported in our study. As with all $\beta$-lactams, the aim of treatment is to maintain serum and tissue concentrations of drug equal to or greater than the MIC for the majority of or the entire dosing interval (Prescott, 2013). Therefore, the label dose can be considered suf-

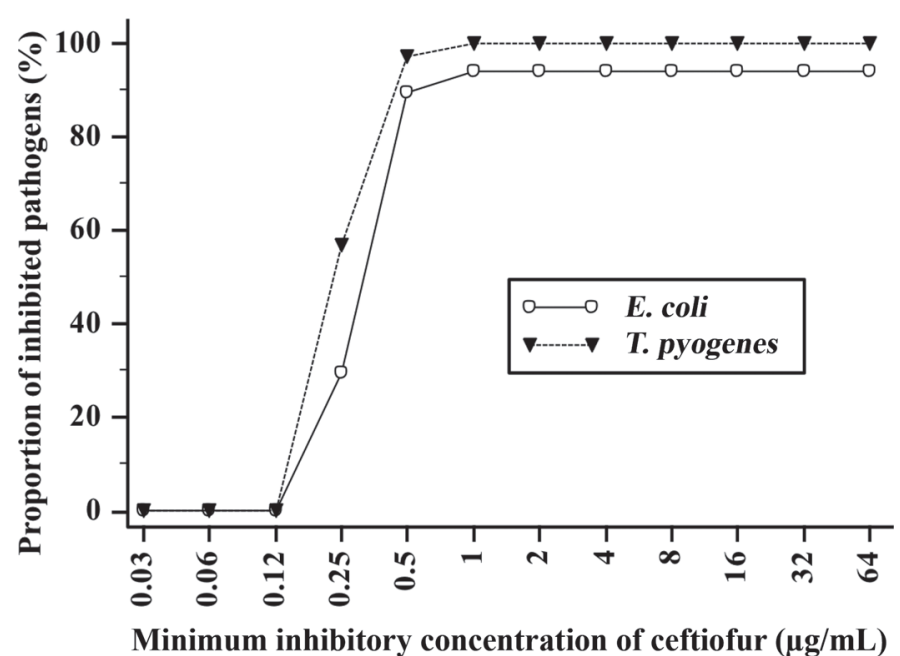

Figure 1. Proportion of Trueperella pyogenes and Escherichia coli that are inhibited by increasing concentrations of ceftiofur. ficiently high to achieve therapeutic concentrations for T. pyogenes as analyzed in this study.

For $E$. coli, the MIC values reported by de Boer et al. (2015) and Sheldon et al. (2004) were lower $(0.5 \mu \mathrm{g} /$ $\mathrm{mL})$ than our result $(1 \mu \mathrm{g} / \mathrm{mL})$; however, our value was comparable to that of Santos et al. (2010b; $1 \mu \mathrm{g} /$ $\mathrm{mL}$ ). The greater MIC for E. coli than T. pyogenes in our study is not surprising because gram-positive organisms (i.e., T. pyogenes) are more susceptible to $\beta$-lactams than gram-negative bacteria (i.e., E. coli), and MIC are lower for gram-positive bacteria (Papich, 2014). With a dosage of $1.1 \mathrm{mg} / \mathrm{kg}$ on 3 consecutive days, the mean maximum concentration of ceftiofur derivates in serum and endometrium exceeded $1 \mu \mathrm{g} / \mathrm{mL}$ (or $\mu \mathrm{g} / \mathrm{mg}$ ) after each injection and in lochia after the second injection (Drillich et al., 2006). Twenty-four and $48 \mathrm{~h}$ after initial treatment, however, measured mean concentrations of ceftiofur were below $1 \mu \mathrm{g} / \mathrm{mL}$ in that study. The optimum duration of plasma concentrations above the MIC is considered to maintain at least 40 to $50 \%$ of the dosing interval (Turnidge, 1998; Toutain et al., 2002; Papich, 2014). As there was no continuous measurement of ceftiofur derivates in blood or tissue in Drillich et al. (2006), it is not clear for how long the concentration exceeded the reported MIC.

Recently, ampicillin has been shown to achieve greater clinical cure rates than ceftiofur in cows with APM (Lima et al., 2014). Moreover, at a dose of $11 \mathrm{mg} /$ $\mathrm{kg}$ of BW every $24 \mathrm{~h}$ for 3 consecutive days, ampicillin concentrated in lochial fluid compared with plasma and reached high median maximum concentrations after first injection of $55.7 \mu \mathrm{g} / \mathrm{mL}$ (Credille et al., 2015). For T. pyogenes, the $\mathrm{MIC}_{90}$ of ampicillin determined in our study was low $(0.06 \mu \mathrm{g} / \mathrm{mL})$, with $81.1 \%$ of all isolates being inhibited at the lowest ampicillin concentration tested, which is in line with a previous report (de Boer et al., 2015; $0.06 \mu \mathrm{g} / \mathrm{mL}$ ). In contrast, more than $30 \%$ of T. pyogenes isolates tested by Santos et al. (2010a) 
POHL ET AL.

Table 5. Summary of MIC of ceftiofur against Trueperella pyogenes and Escherichia coli from 5 studies

\begin{tabular}{llcccc}
\hline Pathogen & Study & $\begin{array}{c}\text { No. of } \\
\text { sampled cows }\end{array}$ & $\begin{array}{c}\text { No. of } \\
\text { analyzed isolates }\end{array}$ & $\begin{array}{c}\mathrm{MIC}_{50}{ }^{1} \\
(\mu \mathrm{g} / \mathrm{mL})\end{array}$ & $\begin{array}{c}\mathrm{MIC}_{90}{ }^{1} \\
(\mu \mathrm{g} / \mathrm{mL})\end{array}$ \\
\hline T. pyogenes & Current study & 141 & 37 & 0.25 & 0.5 \\
& de Boer et al., 2015 & 575 & 35 & 1 & 2 \\
& Santos et al., 2010a & 10 & 72 & 2 & 32 \\
\multirow{5}{*}{ coli } & Sheldon et al., 2004 & 70 & 22 & $<0.06$ & 0.125 \\
& Current study & 141 & 85 & 0.5 & 1 \\
& de Boer et al., 2015 & 575 & 209 & 0.25 & 0.5 \\
& Santos et al., 2010b & 5 & 80 & 1 & 1 \\
& Sheldon et al., 2004 & 70 & 20 & 0.5 & 0.5 \\
\hline
\end{tabular}

${ }^{1}$ Concentrations that inhibited growth of $50 \%$ and $90 \%$ of isolates, respectively.

were not inhibited at the highest ampicillin concentration tested, and the reported $\mathrm{MIC}_{90}$ was $\geq 64 \mu \mathrm{g} / \mathrm{mL}$. Regarding E. coli, $11.8 \%$ of tested isolates were not inhibited at the highest ampicillin concentration tested in the current study and the $\mathrm{MIC}_{90}$ was $\geq 128 \mu \mathrm{g} / \mathrm{mL}$, respectively. The MIC of ampicillin described by de Boer et al. (2015) was $4 \mu \mathrm{g} / \mathrm{mL}$ and that reported by Santos et al. (2010b) was $32 \mu \mathrm{g} / \mathrm{mL}$. Reported median peak ampicillin concentrations at steady state were $5.27 \mu \mathrm{g} / \mathrm{mL}$ in lochial fluid, $3.11 \mu \mathrm{g} / \mathrm{mL}$ in plasma, and $1.55 \mu \mathrm{g} / \mathrm{mL}$ in endometrial tissue (Credille et al., 2015). This illustrates that concentrations of ampicillin in lochia, plasma, and endometrium exceed the $\mathrm{MIC}_{90}$ of T. pyogenes analyzed in our study, whereas the $\mathrm{MIC}_{90}$ of $E$. coli was not reached. In summary, E. coli with high MIC against ceftiofur as well as ampicillin were found in this study. Therefore, susceptibility testing before therapeutic decisions and prudent use of ceftiofur (to maintain it as the last choice for resistant cases of APM) is suggested. The use of other antimicrobials (e.g., ampicillin) should be considered first.

It is clear that many antimicrobials tested in this study showed a bimodal distribution of MIC values. Epidemiological cut-off values divide a wild-type population without acquired or mutational resistance mechanisms to a given drug and a non-wild-type population harboring such resistance mechanisms, and can be used to indicate development of microbiological resistance (Dalhoff et al., 2009). Visual inspection of MIC distributions showed that for T. pyogenes, tetracycline, tilmicosin, ampicillin, amoxicillin, cephalothin and cefoperazone had bimodal distributions, possibly indicating development of resistance against these agents. For E. coli, several tested antimicrobials (i.e., gentamicin, enrofloxacin, trimethoprim/sulfamethoxazole, marbofloxacin, tetracycline, ampicillin, and cephalosporins) also showed a bimodal distribution of MIC. Because $E$. coli is a gram-negative species, intrinsic resistance to some antimicrobials, rather than development of resistance, could explain the high MIC.
Finally, different clinical signs of APM have been assessed as variables potentially associated with MIC. We hypothesized that cows with APM might have pathogens with increased MIC. However, we did not find variation in the distribution of MIC values of ceftiofur for T. pyogenes and E. coli among the 3 study groups. As this is the first study to evaluate differences in MIC for bacteria isolated from healthy cows and those diagnosed with APM, comparable data are not available. Moreover, our results should be interpreted with caution because of the small number of isolates from cows without signs of APM $(\mathrm{n}=3$ and $\mathrm{n}=7$ for $T$. pyogenes and E. coli, respectively) because type II errors might have occurred. One study evaluated MIC of cows with either clinical or subclinical mastitis for Staphylococcus aureus (Oliveira et al., 2012). In that study, MIC of ceftiofur varied between clinical and subclinical cases, whereas differences in MIC for ampicillin were not found (Oliveira et al., 2012).

\section{CONCLUSIONS}

Few data on in vitro susceptibilities of uterus-borne bacteria are available. In this study, MIC of antimicrobials for E. coli and T. pyogenes isolated from cows from 7 farms in Germany were determined and compared with previous findings and with plasma and tissue distributions of ceftiofur and ampicillin. Minimum inhibitory concentrations of ceftiofur were low. However, not all $E$. coli could be inhibited at the highest concentration of ceftiofur tested, which might be an indicator of emerging resistance.

\section{ACKNOWLEDGMENTS}

We thank the farm personnel of the dairy farms as well as the staff of the Institute of Microbiology (Freie Universität Berlin, Germany) for their kind cooperation. A special acknowledgment is given to Aline Poppe of the Institute of Microbiology for her patient advice in 
microbiological techniques. Furthermore, we thank the staff of the Clinic of Reproduction (Freie Universität Berlin) for their support during the practical part of the study. Alina Pohl was partially funded by Tiergyn e.V. (Berlin, Germany).

\section{REFERENCES}

Bradford, B. J., K. Yuan, J. K. Farney, L. K. Mamedova, and A. J. Carpenter. 2015. Invited review: Inflammation during the transition to lactation: New adventures with an old flame. J. Dairy Sci. 98:6631-6650.

Centers for Disease Control. 2015. National action plan for combating antibiotic-resistant bacteria. https://www.cdc.gov/drugresistance/ pdf/national_action_plan_for_combating_antibotic-resistant bacteria.pdf.

Chapinal, N., M. Carson, T. F. Duffield, M. Capel, S. Godden, M. Overton, J. E. P. Santos, and S. J. LeBlanc. 2011. The association of serum metabolites with clinical disease during the transition period. J. Dairy Sci. 94:4897-4903.

Chenault, J. R., J. F. McAllister, S. T. Chester, K. J. Dame, F. M. Kausche, and E. J. Robb. 2004. Efficacy of ceftiofur hydrochloride sterile suspension administered parenterally for the treatment of acute postpartum metritis in dairy cows. J. Am. Vet. Med. Assoc. 224:1634-1639.

CLSI (Clinical and Laboratory Standards Institute). 2013. Performance standards for antimicrobial susceptibility testing; 23rd Informational Supplement. CLSI, Wayne, PA.

Cortinhas, C. S., L. Oliveira, C. A. Hulland, M. V. Santos, and P. L. Ruegg. 2013. Minimum inhibitory concentrations of cephalosporin compounds and their active metabolites for selected mastitis pathogens. Am. J. Vet. Res. 74:683-690.

Credille, B. C., S. Giguère, T. W. Vickroy, H. J. Fishman, A. L. Jones, M. E. Mason, R. O. Dipietro, and D. T. Ensley. 2015. Disposition of ampicillin trihydrate in plasma, uterine tissue, lochial fluid, and milk of postpartum dairy cattle. J. Vet. Pharmacol. Ther. 38:330-335.

Dalhoff, A., P. G. Ambrose, and J. W. Mouton. 2009. A long journey from minimum inhibitory concentration testing to clinically predictive breakpoints: Deterministic and probabilistic approaches in deriving breakpoints. Infection 37:296-305.

de Boer, M., C. Heuer, H. Hussein, and S. McDougall. 2015. Minimum inhibitory concentrations of selected antimicrobials against Escherichia coli and Trueperella pyogenes of bovine uterine origin. J. Dairy Sci. 98:4427-4438.

Dohmen, M. J. W., K. Joop, A. Sturk, P. E. J. Bols, and J. A. C. M. Lohuis. 2000. Relationship between intra-uterine bacterial contamination, endotoxin levels and the development of endometritis in postpartum cows with dystocia or retained placenta. Theriogenology 54:1019-1032.

Dohoo, I. R., S. W. Martin, and H. Stryhn. 2009. Veterinary Epidemiologic Research. 2nd ed. University of Prince Edward Island, Charlottetown, PEI, Canada.

Drillich, M., S. Arlt, S. Kersting, A. A. Bergwerff, P. Scherpenisse, and W. Heuwieser. 2006. Ceftiofur derivates in serum, uterine tissues, cotyledons, and lochia after fetal membrane retention. J. Dairy Sci. 89:3431-3438.

Drillich, M., O. Beetz, A. Pfützner, M. Sabin, H.-J. Sabin, P. Kutzer, H. Nattermann, and W. Heuwieser. 2001. Evaluation of a systemic antibiotic treatment of toxic puerperal metritis in dairy cows. J. Dairy Sci. 84:2010-2017.

EUCAST (European Committee on Antimicrobial Susceptibility Testing). 2013. EUCAST definitions of antimicrobial susceptibility and resistance in relation to "clinical breakpoints" and "epidemiological cut-off value." Accessed May 9, 2017. http://www.eucast.org/ fileadmin/src/media/PDFs/EUCAST_files/EUCAST_SOPs EUCAST_definitions_of_clinical_breakpoints_and_ECOFFs.pdf.

Giguère, S., and R. K. Tessmann. 2011. Rational dosing of antimicrobial agents for bovine respiratory disease: The use of plasma versus tissue concentrations in predicting efficacy. Int. J. Appl. Res. Vet. Med. 9:342-355.

Hellmann, K., and I. Radeloff. 2000. International cooperation on harmonisation of technical requirements of veterinary medicinal products. VICH, Brussels, Belgium. Accessed Oct. 31, 2017. https://www.fda.gov/downloads/AnimalVeterinary/ GuidanceComplianceEnforcement/GuidanceforIndustry/ UCM052417.pdf.

Huszenicza, G., M. Fodor, M. Gacs, M. Kulcsar, M. J. W. Dohmen, M. Vamos, L. Porkolab, T. Kegl, J. Bartyik, J. Lohuis, S. Janosi, and G. Szita. 1999. Uterine bacteriology, resumption of cyclic ovarian activity and fertility in postpartum cows kept in large-scale dairy herds. Reprod. Domest. Anim. 34:237-245.

iMendikament. 2003. Fachinformation: Excenel flow. Accessed May 9, 2017. https://imedikament.de/excenel-flow.

Lima, F. S., L. F. Greco, R. S. Bisinotto, E. S. Ribeiro, N. M. Martinez, W. W. Thatcher, J. E. P. Santos, M. K. Reinhard, and K. N. Galvao. 2015. Effects of intrauterine infusion of Trueperella pyogenes on endometrial mRNA expression of proinflammatory cytokines and luteolytic cascade genes and their association with luteal life span in dairy cows. Theriogenology 84:1263-1272.

Lima, F. S., A. Vieira-Neto, G. S. Vasconcellos, R. D. Mingoti, E. Karakaya, E. Sole, R. S. Bisinotto, N. Martinez, C. A. Risco, K. N. Galvao, and J. E. Santos. 2014. Efficacy of ampicillin trihydrate or ceftiofur hydrochloride for treatment of metritis and subsequent fertility in dairy cows. J. Dairy Sci. 97:5401-5414.

Machado, V. S., M. L. de Souza Bicalho, E. B. S. M. Junior, R. Rossi, B. L. Ribeiro, S. Lima, T. Santos, A. Kussler, C. Foditsch, and E. K. Ganda. 2014. Subcutaneous immunization with inactivated bacterial components and purified protein of Escherichia coli, Fusobacterium necrophorum and Trueperella pyogenes prevents puerperal metritis in Holstein dairy cows. PLoS One 9:e91734.

McDougall, S. 2002. Bovine mastitis: Epidemiology, treatment and control. N. Z. Vet. J. 50:81-84.

NRC. 2001. Nutrient Requirements of Dairy Cattle. 7th rev. ed. National Academies Press, Washington, DC

Oliveira, L., H. Langoni, C. Hulland, and P. L. Ruegg. 2012. Minimum inhibitory concentrations of Staphylococcus aureus recovered from clinical and subclinical cases of bovine mastitis. J. Dairy Sci. 95:1913-1920.

Papich, M. G. 2014. Pharmocokinetic-pharmacodynamic (PK-PD) modeling and the rational selection of dosage regimes for the prudent use of antimicrobial drugs. Vet. Microbiol. 171:480-486.

Parker, K. I., C. W. R. Compton, F. M. Anniss, C. Heuer, and S. McDougall. 2008. Quarter-level analysis of subclinical and clinical mastitis in primiparous heifers following the use of a teat sealant or an injectable antibiotic, or both, precalving. J. Dairy Sci. 91:169-181.

Pohl, A., S. Bertulat, S. Borchardt, O. Burfeind, and W. Heuwieser. 2016. Randomized, controlled clinical trial on the efficacy of nonsteroidal antiinflammatory drugs for the treatment of acute puerperal metritis in dairy cows. J. Dairy Sci. 99:8241-8249.

Prescott, J. F. 2013. Beta-lactam antibiotics: Cephalosporins. Pages 153-173 in Antimicrobial Therapy in Veterinary Medicine. 5th ed. Wiley Blackwell, Ames, IA.

Pyörälä, S., J. Taponen, and T. Katila. 2014. Use of antimicrobials in the treatment of reproductive diseases in cattle and horses. Reprod. Domest. Anim. 49(Suppl. 3):16-26.

Pyörälä, S., and S. Taponen. 2009. Coagulase-negative staphylococciEmerging mastitis pathogens. Vet. Microbiol. 134:3-8

Saini, V., J. T. McClure, D. T. Scholl, T. J. DeVries, and H. W. Barkema. 2013. Herd-level relationship between antimicrobial use and presence or absence of antimicrobial resistance in gram-negative bovine mastitis pathogens on Canadian dairy farms. J. Dairy Sci. 96:4965-4976

Sannmann, I., O. Burfeind, R. Voigtsberger, and W. Heuwieser. 2013. Comparison of two monitoring and treatment strategies for cows with acute puerperal metritis. Theriogenology 79:961-969.

Santos, T. M. A., L. S. Caixeta, V. S. Machado, A. K. Rauf, R. O. Gilbert, and R. C. Bicalho. 2010a. Antimicrobial resistance and presence of virulence factor genes in Arcanobacterium pyogenes 
isolated from the uterus of postpartum dairy cows. Vet. Microbiol. 145:84-89.

Santos, T. M. A., R. O. Gilbert, and R. C. Bicalho. 2011. Metagenomic analysis of the uterine bacterial microbiota in healthy and metritic postpartum dairy cows. J. Dairy Sci. 94:291-302.

Santos, T. M. A., R. O. Gilbert, L. S. Caixeta, V. S. Machado, L. M. Teixeira, and R. C. Bicalho. 2010b. Susceptibility of Escherichia coli isolated from uteri of postpartum dairy cows to antibiotic and environmental bacteriophages. Part II: In vitro antimicrobial activity evaluation of a bacteriophage cocktail and several antibiotics. J. Dairy Sci. 93:105-114.

Scientific Advisory Group on Antimicrobials of the Committee for Medicinal Products for Veterinary Use. 2009. Reflection paper on the use of third and fourth generation cephalosporins in food producing animals in the European Union: Development of resistance and impact on human and animal health. J. Vet. Pharmacol. Ther. $32: 515-533$.

Sens, A., and W. Heuwieser. 2013. Presence of Escherichia coli, Trueperella pyogenes, $\alpha$-hemolytic streptococci, and coagulase-negative staphylococci and prevalence of subclinical endometritis. J. Dairy Sci. 96:6347-6354

Sheldon, I. M., M. Bushnell, J. Montgomery, and A. N. Rycroft. 2004 Minimum inhibitory concentrations of some antimicrobial drugs against bacteria causing uterine infections in cattle. Vet. Rec. 155:383-387.

Sheldon, I. M., G. S. Lewis, S. LeBlanc, and R. O. Gilbert. 2006 Defining postpartum uterine disease in cattle. Theriogenology 65:1516-1530.

Silley, P. 2012. Susceptibility testing methods, resistance and breakpoints: What do these terms really mean? Rev. Sci. Tech. 31:33-41.

Stojkov, J., M. A. G. von Keyserlingk, J. N. Marchant-Forde, and D. M. Weary. 2015. Assessment of visceral pain associated with metritis in dairy cows. J. Dairy Sci. 98:5352-5361.

Thomson, C. J., E. Power, H. Ruebsamen-Waigmann, and H. Labischinski. 2004. Antibacterial research and development in the 21st century-An industry perspective of the challenges. Curr. Opin. Microbiol. 7:445-450.

Toutain, P. L., J. R. E. del Castillo, and A. Bousquet-Mélou. 2002. The pharmocokinetic-pharmocodynamic approach to a rational dosage regimen for antibiotics. Res. Vet. Sci. 73:105-114.

Turnidge, J. D. 1998. The pharmocodynamics of $\beta$-lactams. Clin. Infect. Dis. 27:10-22

US FDA (Food and Drug Administration). 2002. Supplemental new animal drug application NADA 140-890. Accessed May 9, 2017. https://www.fda.gov/downloads/AnimalVeterinary/ Products/ApprovedAnimalDrugProducts/FOIADrugSummaries/ ucm059124.pdf.

Versalovic, J., K. C. Carroll, G. Funke, J. H. Jorgensen, M. L. Landry, and D. W. Warnock. 2011. Manual of Clinical Microbiology. 10th ed. American Society of Microbiology, Washington, DC.

Werckenthin, C., E. Alesik, M. Grobbel, A. Lubke-Becker, S. Schwarz, L. H. Wieler, and J. Wallmann. 2007. Antimicrobial susceptibility of Pseudomonas aeruginosa from dogs and cats as well as Arcanobacterium pyogenes from cattle and swine as determined in the bftgermvet monitoring program 2004-2006. Berl. Munch. Tierarztl. Wochenschr. 120:412-422.

Williams, E. J., D. P. Fischer, D. U. Pfeiffer, G. C. W. England, D. E. Noakes, H. Dobson, and I. M. Sheldon. 2005. Clinical evaluation of postpartum vaginal mucus reflects uterine bacterial infection and the immune response in cattle. Theriogenology 63:102-117.

World Health Organization. 2013. Critically important antimicrobials for human medicine; 4th revision. Accessed Jan. 31, 2017. http:// apps.who.int/iris/bitstream/10665/251715/1/9789241511469-eng .pdf?ua=1.

World Organization for Animal Health (OIE). 2015. OIE list of antimicrobial agents of veterinary importance. Accessed Jan. 31, 2017. http://www.oie.int/fileadmin/Home/eng/Our_scientific _expertise/docs/pdf/Eng_OIE_List_antimicrobials_May2015 .pdf. 